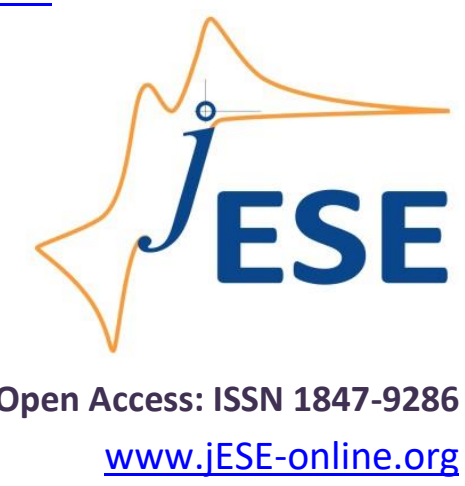

Original scientific paper

\title{
A comparative study of chemical and physical properties of copper and copper alloys affected by acidic, alkaline and saline environments
}

\author{
Samiul Kaiser ${ }^{1}$ and Mohammad Salim Kaiser ${ }^{2, \bigotimes}$ \\ ${ }^{1}$ Department of Civil Engineering, Bangladesh University of Engineering and Technology, Dhaka- \\ 1000, Bangladesh \\ ${ }^{2}$ Directorate of Advisory, Extension and Research Services, Bangladesh University of Engineering \\ and Technology, Dhaka-1000, Bangladesh
}

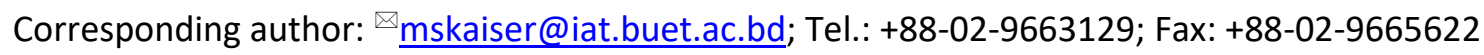

Received: June 11, 2020; Revised: June 29, 2020; Accepted: July 1, 2020

\begin{abstract}
Chemical and physical behavior including corrosion performance, thermal conductivity and visual color change of the copper-based alloys brass and bronze have been studied prior and after corrosion in acidic, alkaline and saline media. The concentrations of $0.5 \mathrm{M} \mathrm{H}_{2} \mathrm{SO}_{4}, 0.5$ $\mathrm{M} \mathrm{NaOH}$ and $0.5 \mathrm{M} \mathrm{NaCl}$ were used in which copper and copper-alloy samples were immersed and left to corrode at room temperature for 28 days. The experiments were performed prior and after corrosion, using conventional gravimetric measurements accompanied with measurements of thermal conductivity, microstructure and optical properties. The color change of different samples was also studied through tristimulus color parameter $\left(L^{*}, a^{*}\right.$ and $\left.b^{*}\right)$ values. It is concluded that the corrosion rate of copper and copper alloys is greater in acidic than in salt and alkaline media. This is due to the extent of disruption of the passive film formed on the surfaces. In the cases of alkaline and salt media, the passive films on the surface remain stable to a large extent. Small increase of thermal conductivity takes place due to formation of a very thin film of oxide and hydroxide bonded to the surface. The environment also affects the color of copper and copper alloys by chemical changes like oxidation and formation of different intermetallics on the surfaces. $A$ microstructural study of experimental materials confirms that corrosion after 28 days results in formation of pores on the surfaces in acidic environment, and passive film that grows thicker on the surfaces in alkaline and saline environments. Aluminum oxide that is more stable than zinc oxide causes better anti-corrosion performance and minimal color variation of bronze compared to brass, especially in acidic environment.
\end{abstract}

\section{Keywords}

Copper-alloys; corrosion; oxidation; thermal conductivity; color; microstructure 


\section{Introduction}

Pure metals like aluminum, copper, iron, etc. are found quite soft in texture. The strength of these materials is gained by adding other elements to the pure metals. In this way alloys are formed [1-3]. Several properties of metals like strength, hardness, corrosion resistance, electrical and thermal conductivity, resistance, change in color, etc. can be increased or reduced through alloying [4-6].

In the case of copper, zinc, tin, aluminum, nickel, manganese, and silicon are usually used in an approximate order of increasing effectiveness to form copper alloys. Brasses and bronzes are considered to be the most renowned families of copper-based alloys which are used frequently in daily works. Brass consists of copper and zinc, while bronze is an alloy of copper combined mostly with tin, but also with other metals like aluminum, phosphorus, manganese, and silicon. Brass and bronze are used in various works, based on their properties. These alloys are used extensively in production of heavy load bearing machine, high-speed operation of shaft sliding sleeves and bush bearings, automobiles, ships, metallurgy, machinery and other industrial fields. At the same time, the application of those alloys is also found in ornamental and building construction industries. Varying amounts and proportions of alloying elements are found in those alloys. Thus, a wide range of properties and variation in color are seen due to the variation of mixtures $[7,8]$.

Brass and bronze are used frequently in different environments and for various purposes as they show outstanding corrosion behavior. Corrosion defines the degradation of metallic materials which is due to various electrochemical and chemical reactions. Corrosion may result into component failure in different industrial environments and it is affected by various environment and metal related factors $[9,10]$.

It is well established in the literature that addition of a substance to improve one property may result by unintended effects on other properties. Although a lot of information can be found about the effects of various alloying elements on the mechanical properties of Cu-based alloys, there is no systematic information on simultaneous changes of other properties [11-13]. Therefore, the present study is focused on evaluating the environmental impact on the physico-mechanical properties of $\mathrm{Cu}$ and $\mathrm{Cu}$ alloys, brass and bronze. This investigation aims to study the effects of ten weight percent (10 wt\%) of alloying elements $\mathrm{Al}$ and $\mathrm{Zn}$, before and after corrosion in $0.5 \mathrm{M}$ acidic, alkaline and saline solutions.

\section{Experimental}

The present study involves copper, brass and bronze samples which were prepared through casting of commercially pure copper, zinc and aluminum. A clay-graphite crucible in a natural gas fired pit furnace was used for melting these experimental alloys. Full chemical compositions of the experimental samples of copper, brass (10.3 wt\% $\mathrm{Zn}$ ) and bronze (9.6 wt\% Al), showing contents of $\mathrm{Al}, \mathrm{Zn}, \mathrm{Pb}, \mathrm{Sn}, \mathrm{Fe}, \mathrm{Ni}, \mathrm{Mn}, \mathrm{Si}, \mathrm{Cr}$, Sb and Cu elements, are given elsewhere $[10,14]$.

The oxide layers from the surface of the cast samples were removed and pieces of $15 \times 20 \times 150$ $\mathrm{mm}$ were cut using a shaper machine. Cold rolling of the cast alloys was carried out with a laboratory scale rolling mill of 10HP capacity at $50 \%$ of reduction. In every pass, about $1 \mathrm{~mm}$ of deformation was given and as a result thickness of the samples was reduced to 7.5 from $15 \mathrm{~mm}$. From the cold rolled samples $5 \times 20 \times 20 \mathrm{~mm}$ coupons were obtained and sanded mechanically with emery papers of rough and finish grade of 1500 grits. The ageing treatment was conducted in an electrical resistance furnace at different temperatures for one hour. Microhardness measurements were carried out on the differently aged samples using a Micro Vickers hardness tester where a load of 1 
$\mathrm{kg}$ and dwell time of 10 seconds were used. A total of seven readings from different locations were taken for every aged sample and average value was calculated.

Corrosion behavior was tested for $50 \%$ cold rolled cast samples of $3 \times 30 \times 42 \mathrm{~mm}$ size that were artificially aged for $60 \mathrm{~min}$ at $300{ }^{\circ} \mathrm{C}$. Prior to use, the samples were sanded with emery paper and cleaned with ethanol. Afterwards, the samples were dried in forced air, weighted (initial weight, $W_{\text {int }}$ ) and exposed to different solutions for periods up to 28 days. Stagnant solutions of $0.5 \mathrm{M} \mathrm{H}_{2} \mathrm{SO}_{4}$, $0.5 \mathrm{M} \mathrm{NaOH}$, and $0.5 \mathrm{M} \mathrm{NaCl}$ were used as aggressive media. After the designated exposure in the solution medium, the samples were removed from the test solution, thoroughly washed with a distilled water, dried well in forced air and weighted again (final weight, $W_{\text {fin }}$ ). The weight loss, $\Delta W$, was calculated in accordance with [15]:

$$
\Delta W=\frac{\left(W_{\text {int }}-W_{\text {fin }}\right)}{A}
$$

where $\Delta W=$ weight loss $\left(\mathrm{mg} / \mathrm{cm}^{2}\right), W_{\text {int }}=$ initial weight prior to the immersion $(\mathrm{mg}), W_{\text {fin }}=$ final weight after exposure $(\mathrm{mg})$ and $A=$ area $\left(\mathrm{cm}^{2}\right)$.

The corrosion rate, $K_{\text {corr }}(\mathrm{mm} /$ year), was evaluated on the basis of

$$
K_{\text {corr }}=\frac{K \Delta W}{T D}
$$

where $K=$ unit conversion constant ( 87.6 for $\mathrm{mm} /$ year unit), $T=$ time of exposure $(\mathrm{h})$ and $D=$ density of metal $\left(\mathrm{g} / \mathrm{cm}^{3}\right)$.

An electric conductivity meter, type 979 was used for measuring the electrical conductivity of the alloys after different immersion conditions. Thermal conductivity was calculated through the Wiedemann-Franz law from measured electrical conductivity data [16]. The images of the corroded samples were taken with a digital single-lens reflex (DSLR) camera to examine the visual changes. The sample images were analyzed through MATLAB software for determining the tristimulus color parameter $\left(L^{*}, a^{*}\right.$ and $\left.b^{*}\right)$ values. The changes of these values with respect to the immersion time in different environments were shown graphically. The washed and dried samples were observed by OPTIKA microscope and some selected photomicrographs were taken.

\section{Results and discussion}

\section{Gravimetric analysis of corrosion effect}

The change of corrosion rate with immersion time for copper, brass and bronze samples, previously aged at $300{ }^{\circ} \mathrm{C}$ for one hour, were calculated using Eq. (1) and Eq. (2). The values of corrosion rate in $0.5 \mathrm{M}$ solutions forming acidic, alkaline and saline environments are plotted in Figure 1(a), 1(b) and Fig. 1(c), respectively.

The corrosion rate $K_{\text {corr }}$ for all experimental material samples is the highest in $0.5 \mathrm{M} \mathrm{H}_{2} \mathrm{SO}_{4}$. The results observed in $\mathrm{H}_{2} \mathrm{SO}_{4}$ media are ascribed to the high aggressive attack of sulphide ions, leading to the disruption of passive films formed on the metal surfaces. However, the corrosion rate is slightly lower than that observed at the earlier stage of immersion, suggesting that the passive films formed on the surface of the experimental samples are stable $[17,18]$. In the case of alkaline solution, the higher corrosion rate at the initial stage could be due to the segregation of copper oxide formed in the matrix. The lower corrosion rate is ascribed to the protective nature of copper hydroxide film formed on the metal surface [19]. After initial time period, corrosion rates start to decrease with time and attain a roughly constant value for all samples. 
a

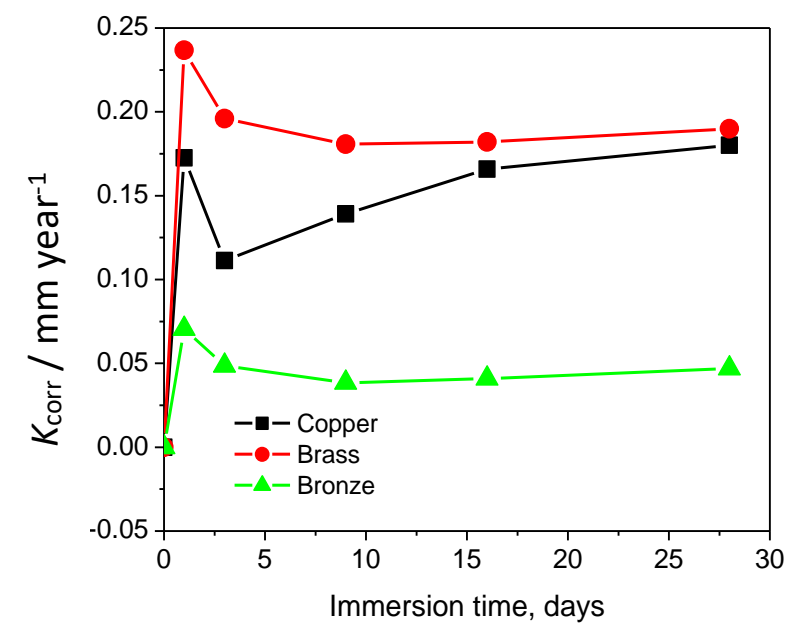

b

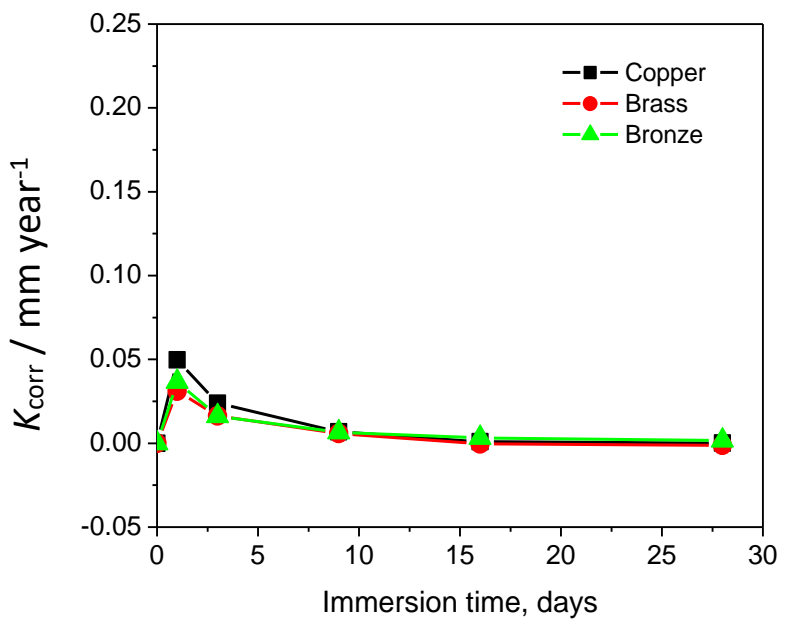

C

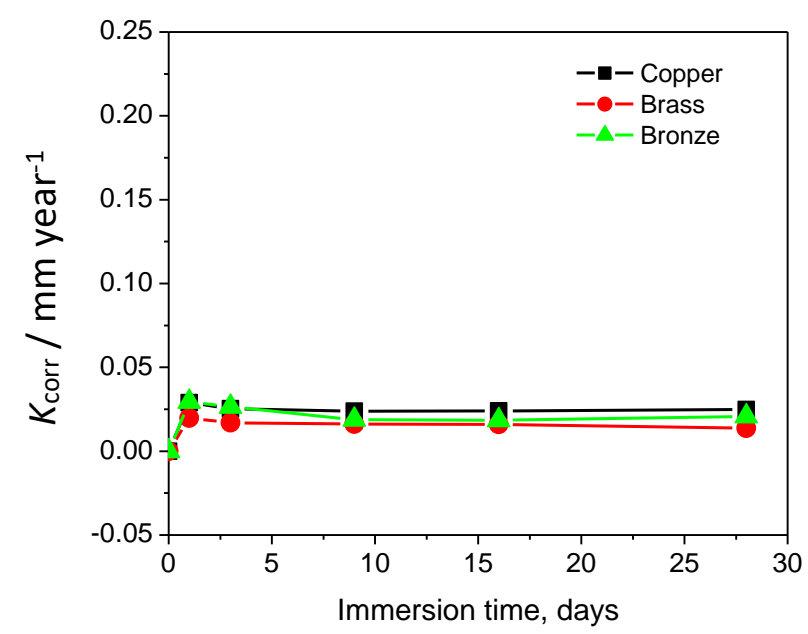

Figure 1. Variation of corrosion rate of copper, brass and bronze with immersion time in (a) acidic, (b) alkaline and (c) saline environment for 28 days

In the case of salt solution, lower corrosion rates are observed for all three materials. In the early stages of corrosion in $0.5 \mathrm{M} \mathrm{NaCl}$ solution, an oxide film grows on the surfaces. The result in the salt solution seems neutral, i.e., neither weight gain nor weight loss was observed. The lower corrosion rate is accredited to the formation of passive films on the surface of the samples, which lead to the temporary seizure of the corrosion attack, while the higher corrosion rate is due to the gradual breakdown of the passive films by the corrosion attack within several days $[20,21]$. Pure copper in acidic solution form $\mathrm{Cu}_{2} \mathrm{O}$ and $\mathrm{CuSO}_{4}$, while brass and bronze form additional $\mathrm{ZnO}$ and $\mathrm{ZnSO}_{4}$, and $\mathrm{Al}_{2} \mathrm{O}_{3}$ and $\mathrm{Al}_{2}\left(\mathrm{SO}_{4}\right)_{3}$, respectively. Dissolution of $\mathrm{CuSO}_{4}$ and $\mathrm{ZnSO}_{4}$ in acidic solution is higher than $\mathrm{Al}_{2}\left(\mathrm{SO}_{4}\right)_{3}$, what caused lower corrosion rate of bronze metal. In addition, $\mathrm{Al}_{2} \mathrm{O}_{3}$ film inhibits the dissolution of the bronze metal. In alkaline and saline media, pure copper forms CuO, while brass and bronze form additional $\mathrm{ZnO}$ and $\mathrm{Al}_{2} \mathrm{O}_{3}$ layers on the surfaces. These layers are very much protective, providing enhanced corrosion resistance $[22,23]$.

\section{Thermal conductivity}

Time changes of thermal conductivity of copper, brass and bronze samples previously immersed in acidic, alkaline and saline media are plotted in Figure 2(a), 2(b) and Fig. 2(c), respectively. In each case, the thermal conductivity of the sample increased initially due to the formation of oxide layer on the surface which caused higher conductivity. After prolonged exposure, the thermal conductivity of the 
experimental materials in acid solution slightly decreased due to the diffusion of aggressive ions leading to porosity of the surface. In $\mathrm{NaOH}$ solution, thermal conductivity decreased because of the formation of black corrosion product layer that becomes thicker with increase of immersion time. A trend of initial conductivity increase, followed by a decrease is observed also in the saline solution within 28 days. Copper forms a very thin film of copper oxide and hydroxide bonded to its surface, increasing the thermal conductivity. The corrosion attack is restored after some days due to the gradual disruption of the passive films which caused conductivity decrease [21,24]. Brass and bronze form additional zinc oxide and aluminum oxide, respectively that together with copper oxide caused small effects on thermal conductivity.

a

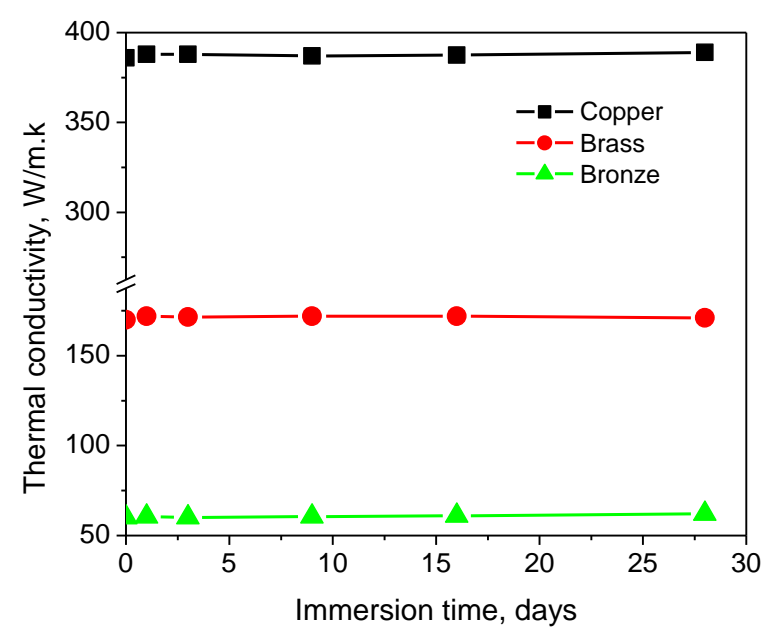

b

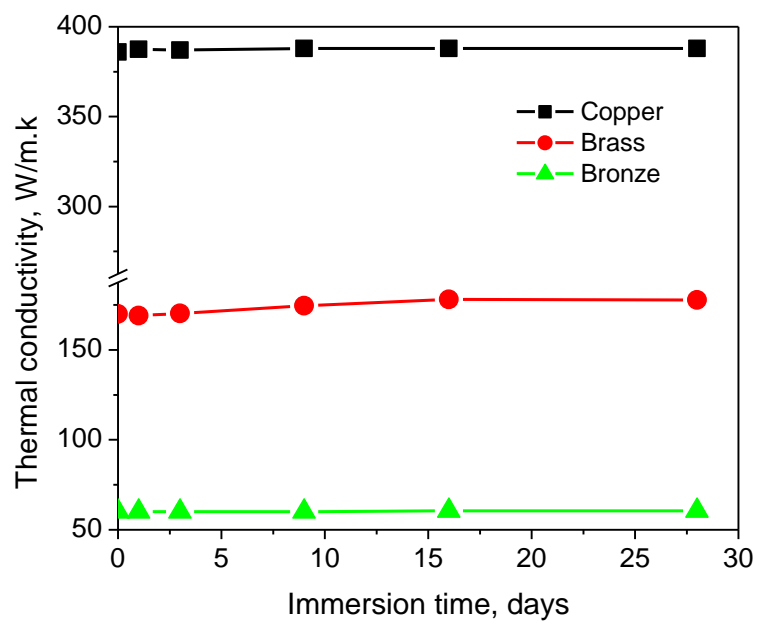

C

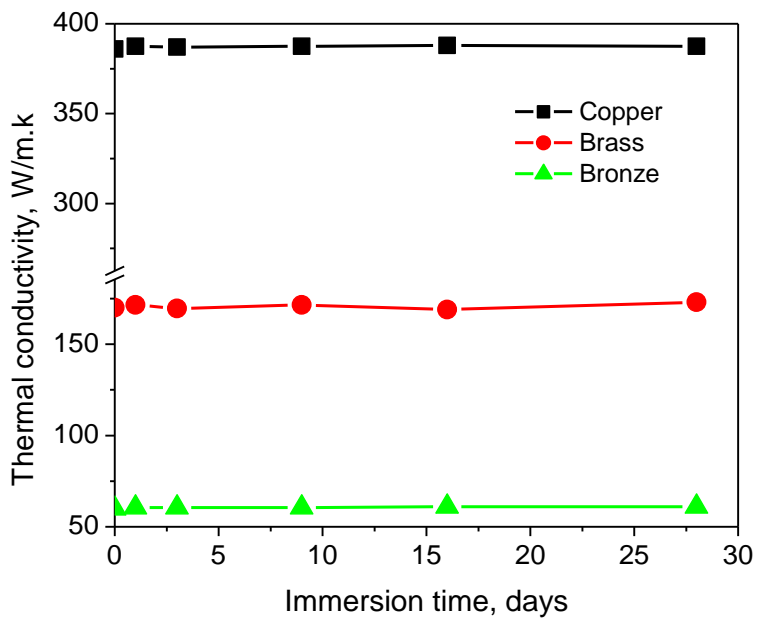

Figure 2. Variation of thermal conductivity of copper, brass and bronze with immersion time in (a) acidic, (b) alkaline and (c) saline environment for 28 days

\section{Optical observations}

DSLR camera optical images of the experimental samples of copper, brass and bronze aged at $300{ }^{\circ} \mathrm{C}$ for one hour before and after corrosion in acidic, alkaline and salt media, were taken at different immersion times and recorded in Figure 3. The images show that polished copper is of a reddish-brown color, the color of brass moves from red to gold, while the color of aluminium bronze is dull gold depending on the levels of zinc and aluminium added to alloy. The surface colors of samples obviously change with increase of immersion time, what points toward the formation of films on the surfaces in different environments. 


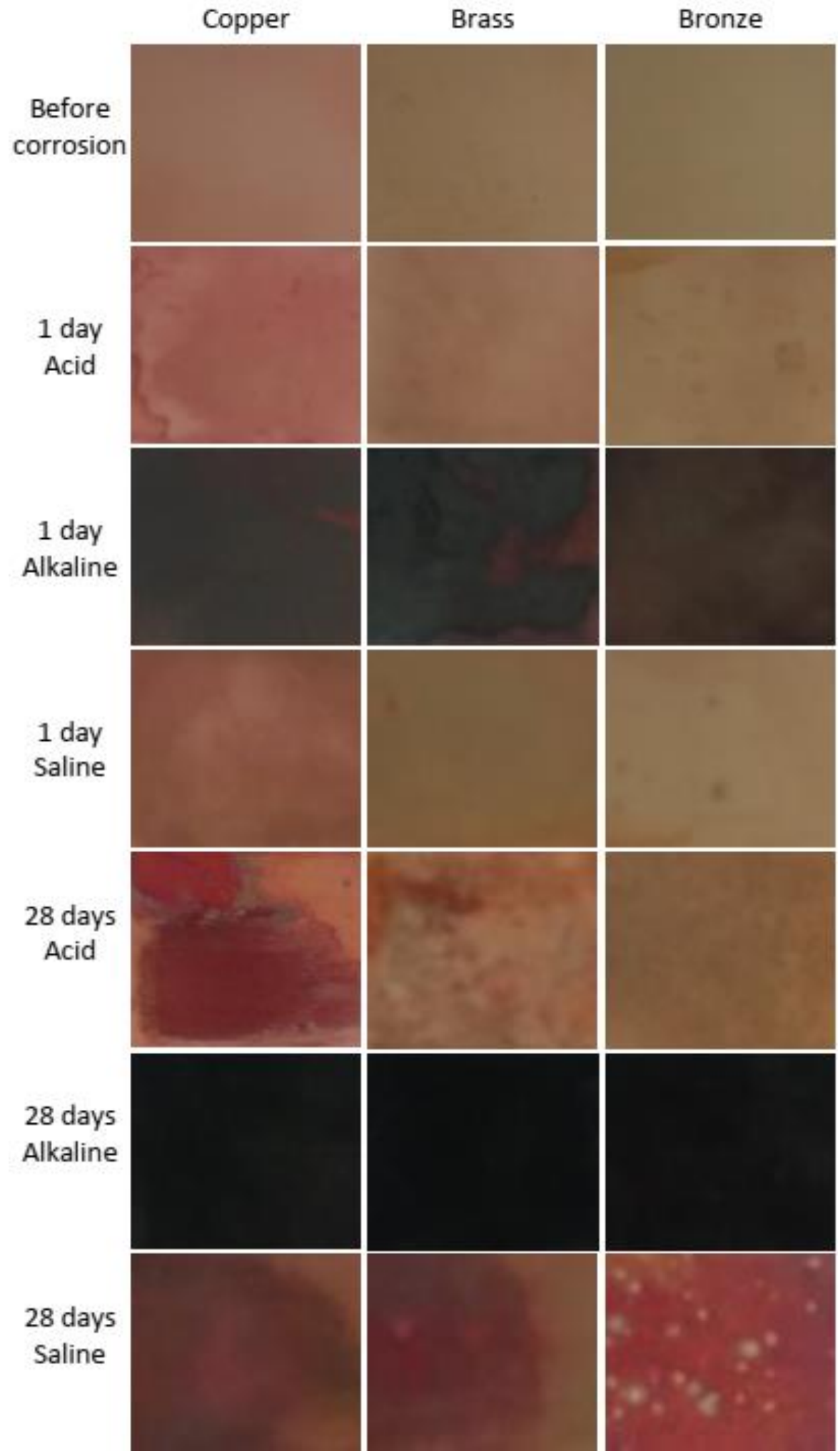

Figure 3. DSLR camera images following color changes of polished copper, brass and bronze samples prior and after corrosion in acidic, alkaline and saline environment for 1 and 28 days

Figure 3 shows that the change of surface color before and after corrosion is more noticeable in the alkaline solution than other environments. In the acidic solution, a mixed film composed of copper oxide and copper sulphate is formed. However, in the presence of the aggressive sulphate ions, the passive film may breakdown continuously and so, the change in color is minimal. After prolonged immersion time, the passive films might be stable, causing higher color variation. After corrosion for either 1 or 28 days in $\mathrm{NaOH}$ solution, the surface colors of all samples have changed 
drastically because of thick black corrosion product layers formed on all surfaces. In the saline environment, copper forms a thin layer of copper oxide and hydroxide which is bonded to its surface. At higher immersion time, the corrosion attack is restored after some days, causing the gradual disruption of the passive film $[25,26]$. For this reason, the color change is minimal in the saline environment. Brass and bronze form zinc oxide and aluminum oxide, respectively, with copper oxide formed in all environments. Aluminum oxide is more protective and so, small variations of bronze color are seen, especially in acidic solution. In alkaline and saline environments, these additional oxides accelerate the color variation. The color change of all three alloys in alkaline solution after 1 day is very strong, but after 28 days the variation is almost indifferentiable due to formation of thick layer of corrosion products at the surfaces.

The color change of all samples is examined by tristimulus color parameter, $L^{*}, a^{*}$ and $b^{*}$ values. $L^{*}$ represents the lightness, where darkest black is at $L^{*}=0$, and brightest white at $L=100$, while $a^{*}$ represents the green-red component of the color, with green and red in the negative and positive direction, respectively. Analogously, $b^{*}$ represents the blue-yellow component of the color, with blue and yellow in the positive and negative direction, respectively. The graphical representations of change of these values with immersion time are shown in Figures 4-6. The variations of $L^{*}$ value with the immersion time in acidic, alkaline and saline solution are shown in Figure 4(a), 4(b) and Fig. 4(c), respectively.

a

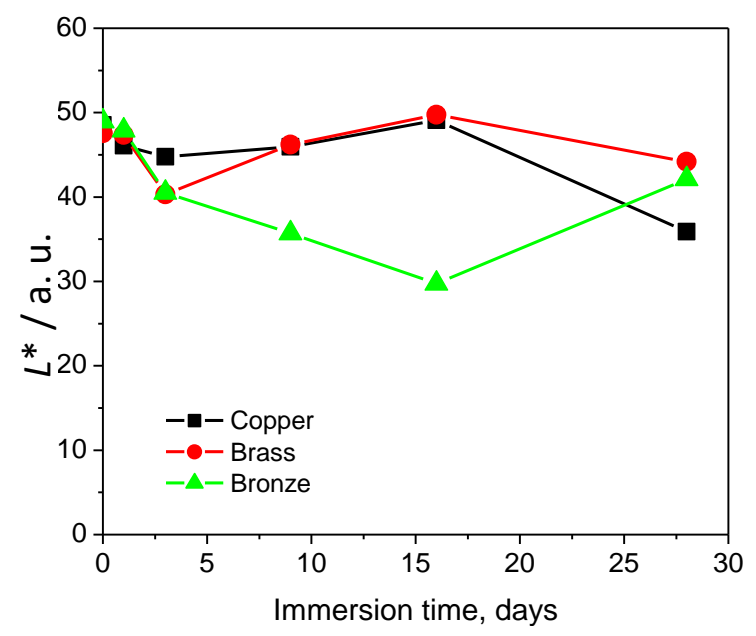

b

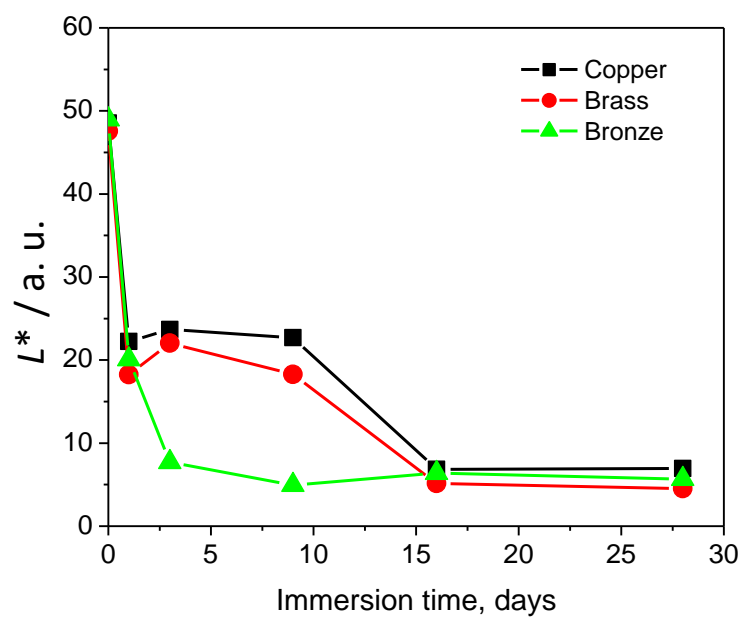

C

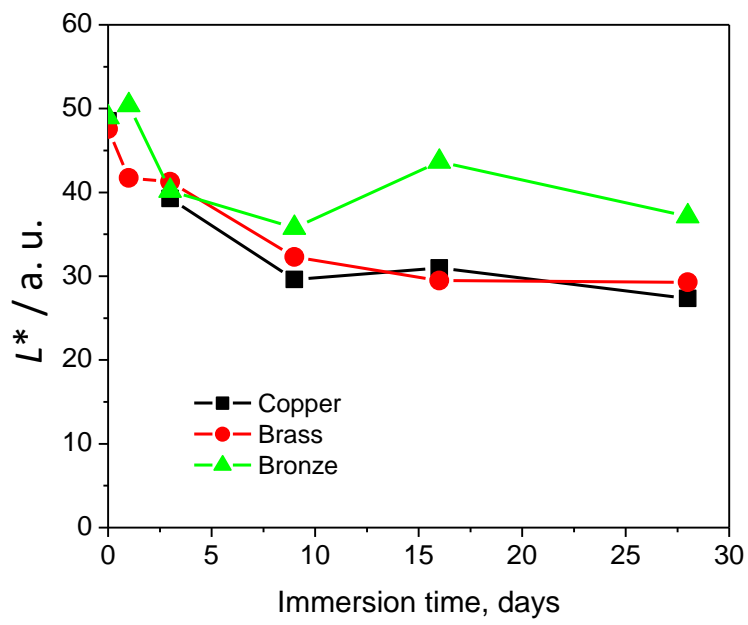

Figure 4. Change of tristimulus color parameter $L^{*}(0=$ black; $100=$ white $)$ of copper, brass and bronze samples with immersion time in (a) acidic, (b) alkaline and (c) saline environment for 28 days 
From the graphs shown in Figure 4 , it is clear that $L^{*}$ value is higher in acidic solution and lower in alkaline solution, while $L^{*}$ value in saline solution is higher than alkaline solution but lower than acidic solution. In acidic solution, the thicker blue layer of hydrated copper sulphate salt $\left(\mathrm{CuSO}_{4} \times \mathrm{H}_{2} \mathrm{O}\right)$ film is formed by a chemical reaction at the surface, what caused decreased $L^{*}$ value. Its intensity is lower because this kind of the oxide film is dissolved more quickly in the acidic solution $[27,28]$. In the case of alkaline solution, copper forms $\mathrm{Cu}_{2} \mathrm{O}$ and light blue precipitate of $\mathrm{Cu}(\mathrm{OH})_{2}$ which are deposited on the surface of the oxide as reported previously $[19,29]$. These layers drastically change $L^{*}$ value of the experimental materials. Similarly, in the saline solution, one has to consider formation of brownish corrosion film consisted of $\mathrm{CuO}, \mathrm{Cu}_{2} \mathrm{O}$ and greenish particles, dicopper chloride trihydroxide $\mathrm{Cu}_{2}(\mathrm{OH})_{3} \mathrm{Cl}[20,30]$. Additional $\mathrm{ZnO}$ and $\mathrm{Al}_{2} \mathrm{O}_{3}$ are formed with $\mathrm{CuO}$ for brass and bronze respectively as discussed earlier. These oxides protect from corrosion, and protect the color of the experimental materials surfaces.

a

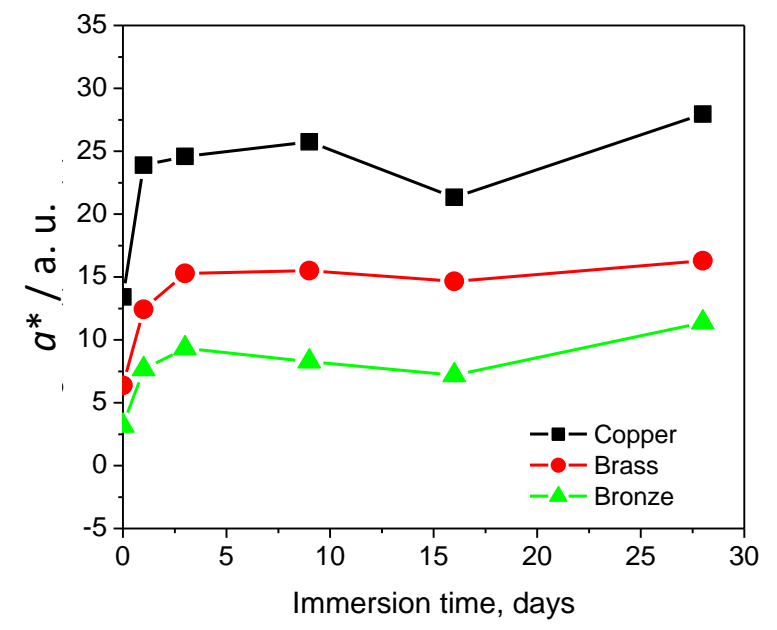

b

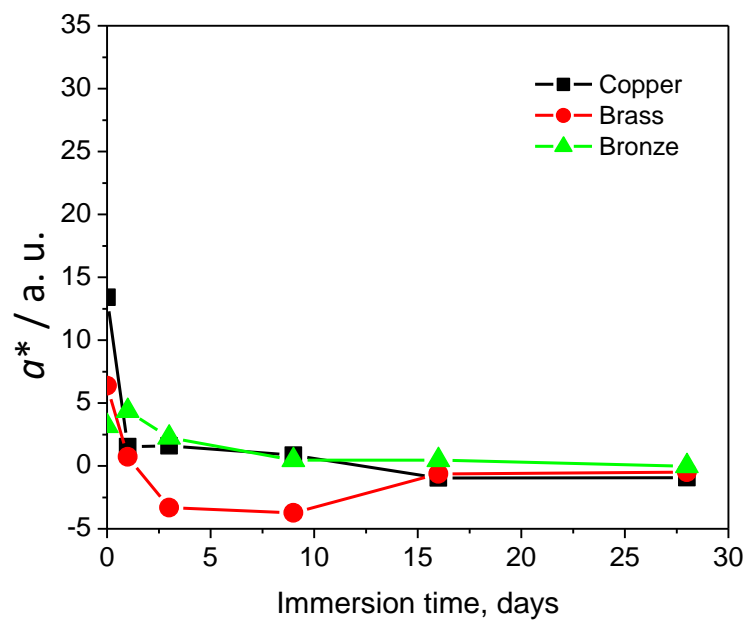

C

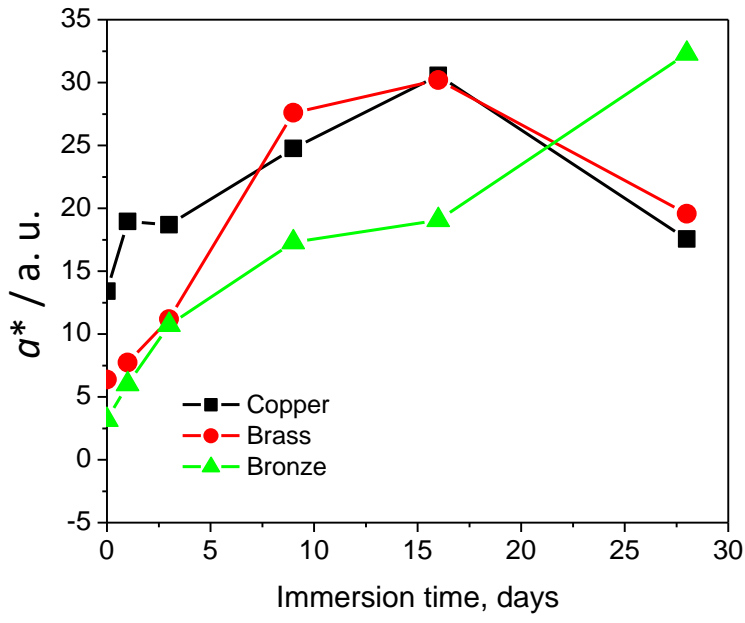

Figure 5. Change of tristimulus color parameter a* (from green (-) to red (+)) of copper, brass and bronze with immersion time in (a) acidic, (b) alkaline and (c) saline environment for 28 days

The $a^{*}$ and $b^{*}$ values $v s$. immersion time graphs for different environments are presented in Figure 5 and Figure 6 , respectively. The graphical scenario shows greater values of $a^{*}$ and $b^{*}$ for acidic and saline solutions, but lower values in the alkaline solution. Quick dissolvement of oxide film in the solution results by less variation of the sample from the original in case of acidic solution. Thus, for all three materials, red and yellow components are more dominant and so $a^{*}$ and $b^{*}$ values are higher for acidic solution. Similarly, the values are higher in the saline condition because of less 
deviation from original colors. But in alkaline condition, deposition of copper oxides provides darker layers on the surface where the green and blue components are dominant. This is the reason of lower values of $a^{*}$ and $b^{*}$ in alkaline condition for all three materials.

In the case of acidic conditions, $a^{*}$ values of brass and bronze are lower than copper because of the presence of $\mathrm{ZnO}$ for brass and $\mathrm{Al}_{2} \mathrm{O}_{3}$ for bronze, which both increase green component of the color. For the same reason, $b^{*}$ value is higher for these two alloys rather than pure copper as yellow component is increased. In alkaline environment all three materials have almost same type of $a^{*}$ and $b^{*}$ values as all the oxide layers sustain over the materials. In salt solution all three materials retain almost their original colors.
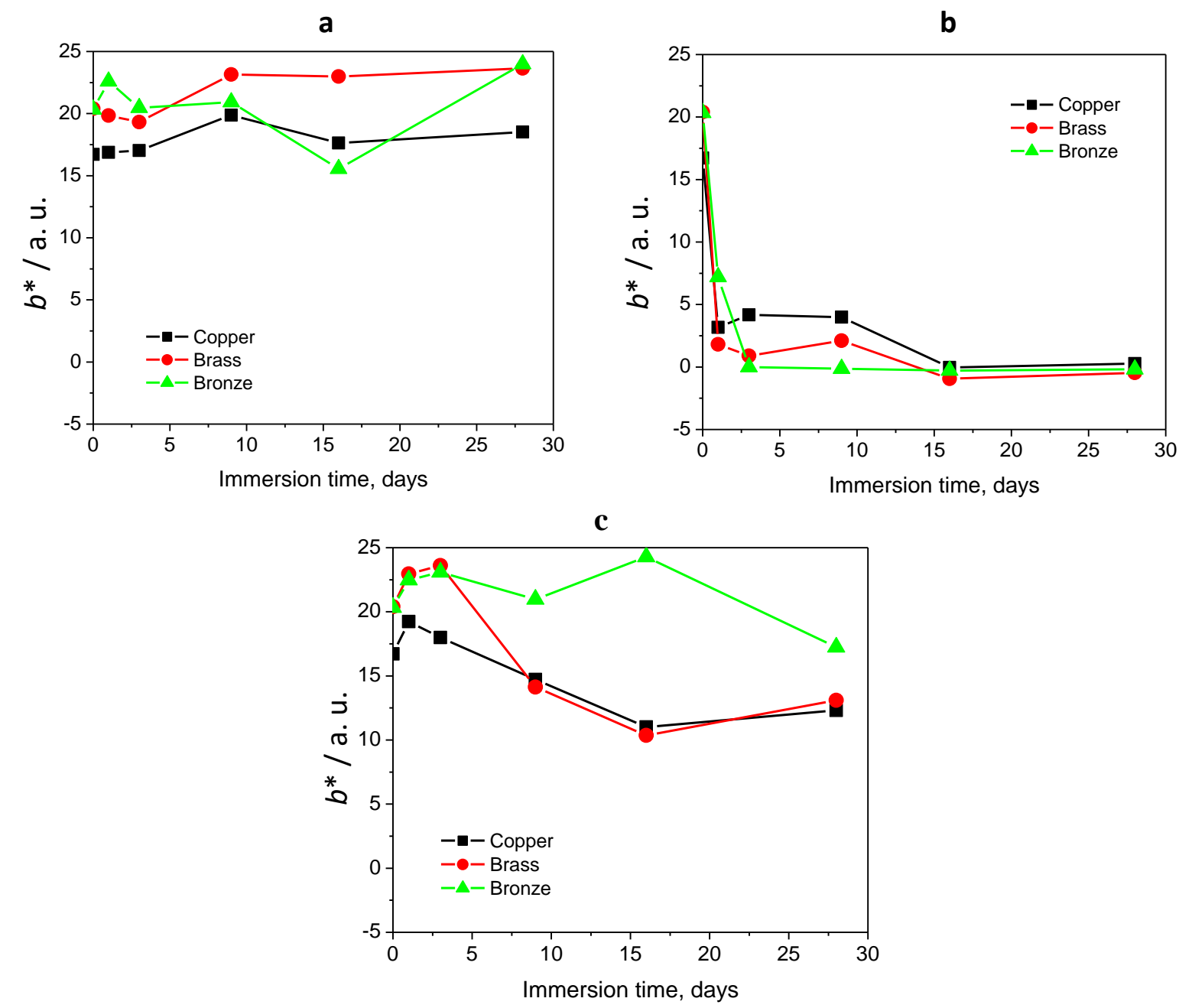

Figure 6. Change of tristimulus color parameter $\mathrm{b}^{*}$ (from blue (-) to yellow (+)) of copper, brass and bronze with immersion time in (a) acidic, (b) alkaline and (c) saline environment for 28 days

\section{Optical microscopy}

The worn surfaces of aged copper, brass and bronze samples before and after immersion in different corrosive environments are presented in Figure 7.

Before corrosion test, all polished materials showed some scratches on the surfaces which may be formed by the sandpaper during surface preparation. It is known that addition of alloying elements changes the grain structure of all alloys. This change in microstructure can be characterrized by the increased dark tone or lighter tone in the micrograph of the experimental materials. Immersed in $0.5 \mathrm{M}$ of acidic, alkaline and saline solution for 1 day, some defects like pits are generally formed in the conversion layers of the experimental materials, but the quantity of the pits per area is relatively low. 


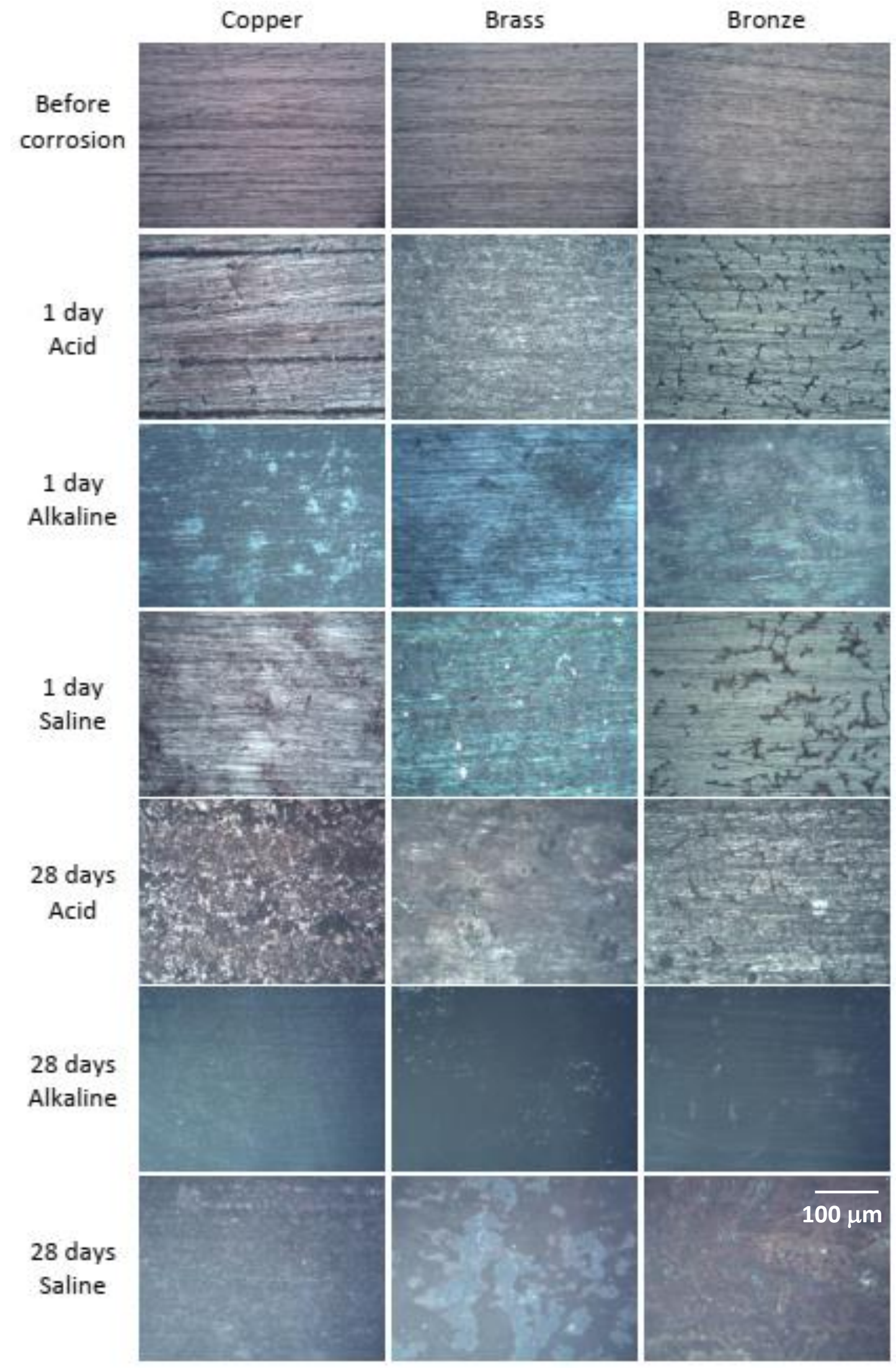

Figure 7. Optical micrographs of the polished copper, brass and bronze prior and after corrosion in acidic, alkaline and saline environment for 1 and 28 days.

The images of the alloys studied after 28 days of exposure in $0.5 \mathrm{M} \mathrm{H}_{2} \mathrm{SO}_{4}$ solution clearly show presence of pores due to the uniform degradation of the alloys [31]. The aggressive attack of the sulphide ions disrupts the passive film formed on the surface of the alloys. The images referring to 
$\mathrm{NaOH}$ solution shows a black corrosion product layers on the alloys surfaces which grow thicker with the corrosion proceeding. It is worth noting that the corrosion layer formed in the alkaline solution seems more compact and homogenous [32]. Also, this layer is not porous. The images obtained in $\mathrm{NaCl}$ solution show presence of passive films on the alloys surface. Only some spots are observed due to the gradual disruption of the passive film [33]. Some variation is observed in cases of brass and bronze. In acidic solution, bronze forms $\mathrm{Al}_{2} \mathrm{O}_{3}$ and $\mathrm{Al}_{2}\left(\mathrm{SO}_{4}\right)_{3}$ which dissolution rate is lower than $\mathrm{Cu}_{2} \mathrm{O}$, and $\mathrm{CuSO}_{4}$ formed by pure copper, and $\mathrm{ZnO}$ and $\mathrm{ZnSO}_{4}$ formed by brass. As a consequence, the minimum pores are formed on the bronze surfaces. Brass and bronze form additional $\mathrm{ZnO}$ and $\mathrm{Al}_{2} \mathrm{O}_{3}$ layer, respectively, with $\mathrm{CuO}$ on the surfaces in alkaline and saline media. Due to this protective layer, brass and bronze surfaces show the extra mark of corroded products [23].

\section{Conclusions}

Copper and copper-based alloys brass and bronze samples showed higher corrosion rate in acid solution compared to alkaline and saline environments, what is due to gradual disruption of passive films and segregation of the copper oxide film in the matrix. It seems that $\mathrm{Al}_{2} \mathrm{O}_{3}$ layer is especially protective in acidic environment, causing the lower corrosion rate of bronze. The thermal conductivity of all three experimental materials increased slightly after corrosion in acid, basic and saline environments due to the formation of oxide layers which decreased surface roughness.

The tristimulus color parameter $L^{*}, a^{*}$ and $b^{*}$ values increase in acidic solution due to formation of blue layer of hydrated copper sulfate $\left(\mathrm{CuSO}_{4} \times \mathrm{H}_{2} \mathrm{O}\right)$ salt film that is dissolved quickly from the surface. The additional production of $\mathrm{ZnO}$ in brass and $\mathrm{Al}_{2} \mathrm{O}_{3}$ in bronze is also responsible for deviations of $L^{*}, a^{*}$ and $b^{*}$ values from pure copper. In alkaline solution, light blue precipitate of copper hydroxide $\mathrm{Cu}(\mathrm{OH})_{2}$ is deposited on the surfaces, what decreases the tristimulus color parameter. Similarly, in the saline solution there is formation of greenish particles, di-copper chloride trihydroxide $\mathrm{Cu}_{2}(\mathrm{OH})_{3} \mathrm{Cl}$, but the gradual breakdown of the passive films brought about by the corrosion attack within several days causes a lower variation in color than in alkaline media. Evidence of formation of crystallographic pitting is found in $\mathrm{NaCl}$ solution for exposure times up to 28 days, while an intensive pit formation is observed in the acidic medium. Aluminum forms a thick film of oxide in alkaline.

Acknowledgements: This experimental work is assisted by DAERS office and the authors would like to thanks to the Department of Chemical Engineering of Bangladesh University of Engineering and Technology, Dhaka1000 for giving the laboratory facilities.

\section{References}

[1] H. Chandler, Metallurgy for the Non-Metallurgist, ASM international, $4^{\text {th }}$ edition, Materials Park, $\mathrm{OH}$, USA, 2006.

[2] J. A. Rogers, Powder Metallurgy 20(4) (1997) 212-220.

[3] S. Kaiser, M. S. Kaiser, International Journal of Mechanical and Materials Engineering 13(9) (2019) 607-611.

[4] M. Kanamori, S. Ueda, Transactions of the Japan Institute of Metals 1(2) (1960) 103-107.

[5] J. Ridhwan, M. Syafiq, R. Hasan, Z. M. Zulfattah, Journal of Engineering and Technology 4(2) (2013) 115-124.

[6] M. Sadayappan, D. Cousineau, R. Zavadil, M. Sahoo, H. Michels, AFS Transactions 110 (2002) 505514.

[7] D. Zhang, Y. Li, K. Feng, P. Zhu, G. Xu, IOP Conference Series: Materials Science and Engineering 452 (2018) Art. 022132. 
[8] M. Modlinger, M. H. G. Kuijpers, D. Braekmans, D. Berger, Journal of Archaeological Science 88 (2017) 14-23.

[9] C. Leygraf, T. Chang, G. Herting, I. O. Wallinder, Corrosion Science 157 (2019) 337-346

[10] S. Kaiser, M. S. Kaiser, Journal of Materials and Environmental Sciences, 11(4) (2020) 551-563.

[11] J. L. Fang, G. McDonnell, Historical Metallurgy, 45(1) (2011) 52-61.

[12] M. S. Kaiser, International Journal of Engineering and Information Systems, 3(11) (2019) 7-14.

[13] E. E. Igelegbai, O. A. Alo, A. O. Adeodu, I. A. Daniyan, Journal of Minerals and Materials Characterization and Engineering, 5(1) (2017) 18-28.

[14] S. Kaiser, M. S. Kaiser, Journal of Sustainable Structures and Materials 3(1) (2020) 1-9.

[15] H. H. Strehblow, Mechanisms of pitting corrosions in corrosion mechanism in theory and practice, Marcel Dekker, New York, 1995.

[16] G. V. Chester, A. Thellung, Proceedings of the Physical Society 77 (5) (1961) 1005-1013.

[17] Y. Konishi, Y. Nakamura, Y. Fukunaka, K. Tsukada, K. Hanasaki, Electrochimica Acta 48(18) (2003) 2615-2624.

[18] M. S. Kaiser, M. Al Nur, Journal of Electrochemical Science and Engineering 8(3) (2018) $241-253$.

[19] N. Fredj, T. D. Burleigh, Journal of the Electrochemical Society 158 (4) (2011) 104-110.

[20] G. Bertolotti, D. Bersani, P. P. Lottici, M. Alesiani, T. Malcherek, J. Schliker, Analytical and Bioanalytical Chemistry 402 (2012) 1451-1457.

[21] M. S. Kaiser, Journal of Chemical Technology and Metallurgy 54(2) (2019) 423-430.

[22] D. Stanojević, D. Tošković, M. B. Rajković, Journal of Mining and Metallurgy 41 B (2005) 47-66.

[23] O. Balogun, J. Borode, K. Alaneme, M. Bodunrin, Leonardo Electronic Journal of Practices and Technologies 24 (2014) 113-125.

[24] S. Li, M. T. Teague, G. L. Doll, E. J. Schindelholz, H. Cong, Corrosion Science 141 (2018) $243-254$.

[25] M. E. A. Dokheily, H. M. Kredy, R. N. A. Jabery, Journal of Natural Sciences Research 4(17) (2014) 6073.

[26] Y. Feng, K. S. Siow, W. K. Teo, K. L. Tan, A. K. Hsieh, Corrosion, 53(5) (1997) 389-398.

[27] R. Otsuka, M. Uda, Corrosion Science, 9(9) (1969) 703-704.

[28] P. Russell, J. Newman, Journal of the Electrochemical Society 134(5) (1987) 1051-1058.

[29] M. Biton, G. Salitra, D. Aurbach, P. Mishkov, and D. Ilzycer, Journal of the Electrochemical Society 153 (2006) 555-565.

[30] X. Liao, F. Cao, L. Zheng, W. Liu, A.Chen, J. Zhang, C. Cao, Corrosion Science 53 (2011) 3289-3298.

[31] Z. Gong, S. Peng, X. Huang, L. Gao, Materials (Basel) 11(11) (2018) Art. 2107.

[32] I. Zaafarany, H. Boller, Current World Environment 4(2) (2009) 277-284.

[33] H. Nady, M. M. El-Rabiei, G. M. Abd El-Hafez, Journal of Bio- and Tribo-Corrosion 3 (2017) Art. 6.

(C2020 by the authors; licensee IAPC, Zagreb, Croatia. This article is an open-access article distributed under the terms and conditions of the Creative Commons Attribution license ( https://creativecommons.org/licenses/by/4.0/) 